\title{
Proactive HRM for reducing knowledge risks - Evaluating commitment and trustworthiness
}

\author{
Olander Heidi, Hurmelinna-Laukkanen Pia
}

This is a Final draft version of a publication

published by World Scientific Publishing

in International Journal of Innovation Management

DOI: $10.1142 / S 1363919615400113$

Copyright of the original publication: (c) World Scientific Publishing

Please cite the publication as follows:

Olander, H., Hurmelinna-Laukkanen, P. (2015). Proactive HRM for reducing knowledge risks Evaluating commitment and trustworthiness. International Journal of Innovation Management, vol. 19, issue 6. DOI: $10.1142 / \mathrm{S} 1363919615400113$

This is a parallel published version of an original publication. This version can differ from the original published article. 


\title{
Proactive HRM for reducing knowledge risks - Evaluating commitment and trustworthiness
}

\author{
Heidi Olander* \\ Lappeenranta University of Technology, School of Business and Management, P.O. \\ Box 20, FIN-53851 Lappeenranta, Finland \\ E-mail: heidi.olander@lut.fi \\ Pia Hurmelinna-Laukkanen \\ Oulu Business School, University of Oulu, P.O. Box 4600, FIN-90014 \\ Oulu, Finland \\ E-mail: pia.hurmelinna-laukkanen@oulu.fi
}

\begin{abstract}
Although the first look might suggest otherwise, knowledge protection is a complex phenomenon that does not lend itself to easy classification. Discussion easily turns to intellectual property rights such as patents or secrecy, while other aspects such as human resource management for knowledge protection is neglected. Yet, innovative firms depend on their knowledgeable employees to generate new innovation, to assist in profiting from them, and maintain the capabilities for later innovative activities. Therefore both reactive and proactive action is needed to mitigate problems with knowledge leaving and leaking. This study addresses the ways in which companies can prepare for knowledge-related risks as early as during employee recruitment. The findings from our case study suggest that somewhat different issues are considered in relation to different types of risks (leaving and leaking), and that while intuition plays a notable role in proactive assessment, a more analytical approach can also be taken.
\end{abstract}

Keywords: Knowledge protection, employees, knowledge leaking, knowledge leaving, HRM-related mechanisms, proactive, recruitment

* Corresponding author

\section{Introduction}

Innovative firms depend on their knowledgeable employees to generate new innovation, to assist in profiting from them, and maintain the capabilities for later innovative activities. The problem is that the allegiance of the employees towards the company may vary, thereby causing problems related to knowledge transferring out of the company with departing employees. Such knowledge leaving can cause significant if not irretrievable damage to organisational memory (Alvesson, 2000) or social networks required for the creation and transfer of tacit knowledge (e.g. Currie and Kerrin, 2003; Storey and Quintas, 2001). The problem deepens notably if the knowledge, once outside, is utilised for competitive purposes (e.g., if the leaving employee starts a business of his/her own or joins a competing organisation), which erodes the competitive advantages of the firm from two ends: the firm (with lost assets) and the markets (with others utilising assets lost by the firm). 
Knowledge-related risks also emerge during employment relationships. In addition to the risks of leaving, it may be that employees' awareness of their knowledge-related responsibilities and information security is not as high as it is assumed to be - and/or as high as it should be, which can cause knowledge leaks that harm the firm's competitive positioning (Bulgurgu et al., 2010). Aside unintentional knowledge leakages, intentional ones may also happen. While sometimes the harm can be minimal or contained with intellectual property rights, for example, in the worst situations knowledge is copied and exploited by competing organisations. Harmful effects may also emerge when the leaked knowledge is not imitated as such: as a result of non-excludability some knowledge assets being out in the open may essentially reduce the ability of the firm to charge its customers based on the use of the (innovative) offerings (see e.g., Grossman and Helpman, 1991, on public good nature of knowledge). Therefore finding ways to address these issues as early as possible can be considered to be important for any innovative company.

Intellectual property rights (IPRs) and other such mechanisms can provide the basis for knowledge protection and appropriation strategies, but when acknowledging the importance of employees, other directions are also worth exploring. In terms of governing, balancing knowledge sharing and protection, and preparing for knowledge leaving and knowledge leaking -types of risks in particular, firms have several human resource management (HRM)-related means at their disposal (e.g., Liebeskind, 1996). Some of the mechanisms are reactive, a company's HRM-system-based means to respond to occurring leaking ex post. Others are more proactive means to prepare for knowledge leaking and leaving, with the aim to influence the employee conduct ex ante, before knowledge risks realise. However, the majority of these means - although proactive - can only be relied on to mitigate knowledge risks once the employees are already within the company, and they are only as viable in managing knowledge risks as they are feasible in guiding the employees that the firm already has.

Even more proactive approaches would be those that the firm can use already during the recruitment process, before the employment relationship even starts (i.e., ex ante employment). Such approaches have not received as much attention, however. Recruitment-related discussion rather addresses the fit between the applicant and the hiring organisation and other such issues (e.g., O’Reilly et al., 1991; Kristof, 1996; Gardner et al, 2012) rather than protective aspects. The closest that the research gets in linking recruitment to knowledge risks seems to be through connecting recruitment with keeping the organisation in business in case of high personnel turnover or lack of resources (Haesli and Boxall, 2005; Han and Froese, 2010; O'Neill and Adya, 2006; O'Reilly et al., 1991) that is, it seems that recruitment is treated as a remedy to the outcomes of knowledge risks (particularly knowledge leaving). The problem is that at the same time constant recruiting - especially combined with active knowledge sharing - may actually lead to key knowledge being lost to rivals (Haesli and Boxall, 2005). This leaves recruitment-related discussion quite inconclusive with regards to knowledge preservation. On the other hand, in R\&D management literature, retention has been the interest for quite a few years (Chang et al., 2008; Hofer-Alfeis, 2008), but while the respective literature focuses on committing and keeping the existing personnel within the firm, it does not really reach the recruitment phase.

In sum, recruiting or browsing for, or selecting, potential employees and paying attention to knowledge protection are seldom considered simultaneously. Detailed discussion, in particular, is scarce and those mechanisms that are in place to more proactively contain knowledge leaving and leaking in the first place-Proactive HRM- 
related means - are rarely addressed. While one reason may be that organisations naturally need to focus on retrieving the best talent and the focus cannot be on knowledge protection issues, the risk taking could be better informed if the indicators for potential problems were found early on.

Based on the argumentation above, in this study we focus on the phase of evaluating potential employees, i.e. recruitment, and empirically try to find answers to the research question of: What are the ways in which companies can prepare for knowledge-related risks in employee recruitment? Our aim thus is to see what organisations do (e.g., what kind of information they use and how they utilise it) to detect knowledge leaving and leaking tendencies and the possibilities to take into account these tendencies early on.

In the following, literature is first scrutinised to gather an overview of existing knowledge on the topic and to provide a basic understanding on the relationship between recruitment and knowledge protection. For empirical examination, we chose a case-study approach with two high-technology companies from two different industries, as they "rely on highly skilled employees to innovate and develop new products and are therefore an ideal environment for exploring the strategies employed for both managing knowledge, and recruiting and retaining employees." (Haesli and Boxall, 2005, p. 1955) The two multinational companies examined have headquarters and R\&D in Finland, and R\&D units in the US and China, among other countries. We carried out semi-structured face-to-face interviews with 50 knowledge workers. The sample covering two industries and three continents enables wider analytical generalisability of the results. We analysed the data with template analysis logic in conducting content analysis, using themes arising partly from theory and partly supplemented by the data (e.g., Bowen, 2006). The discussion on the findings concludes the paper together with theoretical contribution, managerial implications and suggestions for future research.

\section{Knowledge leaving and leaking risks inducing need for proactive approach to knowledge protection}

Knowledge protection - especially in an era with an open approach to innovation, knowledge sharing and other such highlighted aspects - is quite a controversial topic. Depending on the point of view taken (organisational, social, etc.), knowledge protection or strong appropriability regimes are seen as beneficial or detrimental at the extremes, and irrelevant in the middle (e.g., Belderbos and Somers, 2015; Dahlander and Gann, 2010; Dosi et al., 2006; Todorova and Durisin, 2007; West, 2006). In this study, we choose to adopt the point of view of an innovating organisation that has a genuine need to preserve its core knowledge in order to secure future innovation. We also assume that much of the valuable knowledge resides in employees, and that in the high-technology companies, among key knowledge workers, the issues related to knowledge management are clearly a strategic concern (Haesli and Boxall, 2005). From this starting point, we get to the expectation that employees' movement and behaviour with respect to knowledge preservation are of relevance (see, e.g., Hannah and Robertson, 2015; HurmelinnaLaukkanen and Puumalainen, 2007). In other words, we assume that both knowledge leaving and leaking are of concern (Olander and Hurmelinna-Laukkanen, 2015a). Knowledge leaving, i.e. turnover, is expensive to the company not only because of the costs related to continuous recruiting, socialising newcomers and training related to the focal tasks, but also because of the costs that are difficult to quantify when losing irreplaceable 
knowledge assets (Mitchell et al., 2001; O'Neill and Adya, 2006). Knowledge leaking, in turn, may reduce possibilities to capture value from it. While different mechanisms are available to deal with these aspects, the HRM-related mechanisms have high potential in producing expected outcomes in balancing knowledge protection and sharing (Rousseau and Wade-Benzoni, 1994; Liebeskind, 1996, 1997; Hurmelinna-Laukkanen et al., 2015; Norman, 2001, Norman, 2002).

Bulgurcu et al., (2010), Hannah and Robertson (2015) and Liebeskind (1996, 1997), Olander and Hurmelinna-Laukkanen (2015) among others, address some HRM-related mechanisms that may ease the problem with knowledge leaving and leaking. These can be categorised according to their formality, for example (Olander et al., 2014), but also according to the phase in which they are applied, and where (geographically and culturally) they are most suitable (Olander and Hurmelinna-Laukkanen, in press).

First, reactive HRM-related means include, for example, reactions to employees' mishaps in treating confidential knowledge or sanctions related to revealing firm-specific trade secrets (e.g., Bulgurcu et al., 2010; Rousseau and Wade-Benzoni, 1994). The problem is that the reactive mechanisms are reactive, which means that they only come into play when the harm has already occurred, when the knowledge risks have materialised. If the firm wants to diminish the likelihood of the risks emerging, it may have to augment its perspective.

Other, more proactive mechanisms have been noted to consist of offering education and career paths, and appreciation and acknowledgement to increase trust and commitment. Paying bonuses only after a specified period of employment also provides the incentives to stay within the firm (Liebeskind, 1996, 1997), which could be useful especially when dealing with knowledge workers whose commitment has been noted to be more occupational and less motivated by the employing organisation (O'Neill and Adya), and whose turnover can thus be higher than that of other groups (Despres and Hiltrop, 1995). Signing of NDAs, offering guidance with regard to knowledge protection policies of the firm, or induction and exit interviews can likewise act as a preventive tool, especially with regard knowledge leaking. In addition, the effects of knowledge-related risks can be proactively reduced by capturing knowledge in databases and monitoring and restricting employee access to knowledge assets (Bulgurcu et al., 2010). The challenge, especially in knowledge work, is that experts and professionals cannot really be strictly supervised or guided in their work, nor is this practical (Bligh et al., 2006). Employees generating innovative solutions need to be able to work relatively freely and take charge of their own work at least to an adequate extent (Bligh et al., 2006; Hannah and Roberson, 2015).

What may help resolve this is shifting attention to the recruitment phase. Through such an approach, proactiveness can be taken even further to cover the aspects related not only to diminishing the likelihood of existing risks realising, but also to creating favourable premises that actually reduce the knowledge risks at their origins: hiring such employees that are likely to stay within the firm and are capable and willing to look after its benefits eases the situation. Besides, considering the knowledge risk and their management potential at the recruitment phase avoids the need of having too many limiting structures in the actual work.

It has been suggested that the employing organisation likely attracts such employees that can find the values of the organisation to be in line with their own (e.g. O'Reilly et al., 1991; Tyler, 2003; Tyler and Blader, 2005), and if the image of the firm resonates values of loyalty and commitment, it is more likely that it will end up having personnel with these traits. Surely, as mentioned above, the balance between knowledge protection and sharing 
is a complex, even controversial issue, meaning that it may not be the easiest thing to communicate correctly. This means that it may not come out accurately when this type of fit is considered: a tight orientation to knowledge protection may give the firm a negative imprint, especially among innovative employees appreciating and accustomed to interactive approaches (Cisco corp. 2014; Hannah and Robertson, 2015; Horwitz et al., 2003; Paré et al., 2001; Vanhala and Ahteela, 2011). Generating the opposite image, on the other hand, may lead to disappointments when employees encounter restrictions. These disappointments may actually induce knowledge leaving and leaking (see, e.g., Lin and Kuo, 2007).

The presence of the aforementioned limitations does not, however, prevent the managers of the firm to evaluate such attributes of prospective employees during recruitment that may have a bearing in terms of knowledge protection later on. The goal is, after all, to select such employees that can be relied on in this respect. The problem is that the way these qualities are identified is not completely clear from existing literature. It is not yet known what exactly should be paid attention to during recruitment processes. Therefore, in the following we approach this through a practical case example.

\section{Methods}

For the empirical research on the issues at hand, we used qualitative interview data gathered from 50 employees of two globally operating technology companies' R\&D units. We selected the R\&D units of the companies for examination, as these units and their employees are highly involved in knowledge-intensive innovation activities and inter-firm collaborative innovation where knowledge sharing takes place. Hence, the employees we interviewed can be called knowledge workers. This setting enables examination to take place in companies where knowledge issues related to $R \& D$ employees play a role. A combination of theoretical and purposive sampling was applied when selecting the organisations, and we used the companies as instrumental case studies describing the phenomenon in certain contexts rather than intrinsically examining these cases (Silverman, 2005, p. 127-131).

One of the case companies is in the ICT industry, and the other is in the high-tech engineering industry. We interviewed 20 employees from the ICT industry company, and 30 from the engineering industry company. Both firms have their headquarters in Finland. We gathered data through semi-structured theme interviews in three countries where the companies had R\&D units: in Finland, the US and China. Having case companies from two different industries and three different continents improves the generalisability of the findings.

We conducted the interviews throughout the organisational levels: we interviewed operative R\&D employees, team leaders, managers (HR, R\&D) and strategy level employees. We selected informants based on their personal involvement in $R \& D$ collaboration and confidential knowledge. Each interview lasted between 90 to 120 minutes, and they were transcribed from recording with the permission of the interviewees.

Regarding the handling of the data, we employed template analysis logic in conducting inductive content analysis, using themes (Franzosi, 2006) arising partly from theory and partly supplemented by the data. According to Bowen (2006, p. 14), qualitative research, even grounded theory (that has a highly inductive nature involving the "researcher's attempts to discover, understand and interpret what is happening in the research context" 
without preconceived notions as a starting point) requires "sensitising concepts" as interpretive devices to where research starts (Glaser, 1978; Patton, 2002). Sensitising concepts give a general sense of reference and guide approaching empirical instances (Blumer, 1954). Employing sensitising concepts such as knowledge leaving and leaking providing the frames, we approached the data looking for indications of the interviewees' perceptions on how companies already proactively prepare for the two types of knowledge risks when selecting the employees. Further, we looked for issues related to interviewees' perceptions on which issues reduce the knowledge-related risks if they are paid attention to early on. We were interested in discovering which kinds of assessment were used, and therefore specifically avoided leading the interviewees to speculate further than what had been noticed by the interviewees themselves. This enabled us to restrict our observations to relevant themes, and see what the situation was in the organisations at the moment of the enquiry.

In order to simplify the complexity of the data (multilevel, multi-country setting), and to find repeated patterns to expand theory, we analysed the data - following Yin's (2003) case study logic - as a whole instead of making distinctions between levels or countries. In conducting the analysis, we followed steps introduced in Gioia et al. (2013) to conduct the analysis using the approach where researchers are able to transparently show the analysis path from the data through coding into final results, thereby generating the theory.

In applying the phase of open coding of the analysis method, we first coded the whole data looking for cues related to assessing the potential employee in the recruitment context in terms of knowledge protection issues. This was done by assigning to each quote a content-describing label. Already at this stage, we made a distinction between knowledge leaving and leaking, coding the findings according to interviewees' mentioning individual means of assessment and other such aspects in association to each of these two contructs (see Appendices A and B). In the next phase we combined quotes with similar ideas under the same labels and rephrased some of the labels to better fit the overall content. After several rounds of iteration these labels were arranged into tables, and the labels became the 1 st order concepts described in Appendices A and B. Next, in applying the phase of axial coding we looked for common features in these $1^{\text {st }}$ order concepts and, depending on their contents, collected them under the $2^{\text {nd }}$ order themes.

After this phase, we could see that each of the grouped dimensions was related to either commitment or trustworthiness that through selective coding became the aggregated dimensions in our analysis. At this point we also made visible the connection of commitment and trustworthiness to the knowledge leaking and leaving risks: we noticed that when asked about knowledge leaving, commitment-related aspects came out in the interviews, whereas when discussing knowledge leaking, issues related to trustworthiness were more emphasized by the interviewees. At this stage, we also connected the empirical findings to the surrounding theoretical discussion: we conducted literature searches regarding especially the concepts and issues discovered from the empirical data and analysis. Thereby the findings from the analysis were used to construct theoretical discussion. 


\section{Findings - How do we find and hire employees that wish to stay and adapt to knowledge protection procedures?}

Table 1 illustrates the aforementioned procedures and summarises the findings. More details on the data behind the concepts are described in the Appendices.

Table 1. Analysis path from $1^{\text {st }}$ order concepts through $2^{\text {nd }}$ order themes to aggregate dimensions.

\begin{tabular}{|c|c|c|}
\hline $1^{\text {st }}$ order concepts & $2^{\text {nd }}$ order themes & Aggregate dimensions \\
\hline $\begin{array}{l}\text { Search for long term } \\
\text { employees - Stability }\end{array}$ & \multirow[t]{2}{*}{ Indicators of commitment } & \multirow[t]{6}{*}{ Commitment } \\
\hline $\begin{array}{l}\text { Duration of previous } \\
\text { employments }\end{array}$ & & \\
\hline Assessing motivation & \multirow{3}{*}{$\begin{array}{l}\text { Means to assess } \\
\text { commitment }\end{array}$} & \\
\hline Holistic interviews & & \\
\hline Psychological tests & & \\
\hline Competitive situation & Context of commitment & \\
\hline $\begin{array}{l}\text { Openness about previous } \\
\text { employer }\end{array}$ & $\begin{array}{l}\text { Indicators of willingness } \\
\text { to limit knowledge } \\
\text { leaking }\end{array}$ & \multirow[t]{7}{*}{ Trustworthiness } \\
\hline Using referrals & \multirow{2}{*}{$\begin{array}{l}\text { Means to assess } \\
\text { capabilities to protect } \\
\text { knowledge }\end{array}$} & \\
\hline Assessing awareness & & \\
\hline $\begin{array}{l}\text { Using intuition to assess } \\
\text { general trustworthiness }\end{array}$ & \multirow{4}{*}{$\begin{array}{l}\text { Means to assess } \\
\text { willingness to protect } \\
\text { knowledge }\end{array}$} & \\
\hline Psychological tests & & \\
\hline Background checks & & \\
\hline $\begin{array}{l}\text { Analysing the history of } \\
\text { applicants }\end{array}$ & & \\
\hline
\end{tabular}

The examination of the empirical data revealed some general patterns with regard to knowledge risks and the recruitment activity. First, combining the information gained from interviewees and the theory, it seems that aspects related to commitment go together with addressing the knowledge leaving risk, while trustworthiness is more closely related to addressing the knowledge leaking risk. When the interviewees described issues related to knowledge leaving, they referred to different indicators of and means to assess commitment, as well as contextual issues related to leaving tendencies. Likewise, when knowledge leakages were discussed, indicators of and means to assess trustworthiness emerged. This finding matches with theory as well: committed employees are not likely to leave the firm (Colbert et al., 2000; Fiorito et al., 2007), and if they are trusted with confidential information, they are likely to take care of it (Hannah, 2005). The results of our analysis further hint towards evaluation of commitment being deemed more important than evaluation of employees' trustworthiness. This indicates that addressing the knowledge leaving risk through proactive HRM practices is essential. This is especially important since reactive HRM practices in general do not seem to work particularly well in preparing for leaving risks (but rather work for knowledge leakages; see e.g., Liebeskind, 1996; 1997; Bulgurcu, 2010; Hurmelinna-Laukkanen et al., 2015). In the following we will elaborate on the finding regarding trustworthiness and commitment in more detail. 


\subsection{Proactive approach of evaluating trustworthiness}

Earlier research has linked evaluation of trustworthiness mainly with managerial trust, where the elements of trustworthiness include multiple issues such as competence, consistency, fairness, integrity, loyalty, openness, receptivity, benevolence and value congruence (Butler, 1991; Cho and Perry, 2012; Larzelere and Huston, 1980; Sitkin and Roth, 1993). However, in most cases these apply rather to existing relationships than recruitment situations. Mayer et al. (1995) synthesise these elements into three core factors of perceived trustworthiness, calling them ability, benevolence, and integrity. These evaluations are often presented in light of the employees' trust towards the employer, apart from a few exceptions covering the employer's trust towards the employee (Brower et al., 2009; Tzafrir, 2005), however, these do not usually cover the assessment of potential employees. The categorisations, however, come close to our findings from the data, thereby enabling us to mirror them with our findings on situations where employers evaluate potential employees in terms of their trustworthiness.

From the empirical findings regarding trustworthiness, two aspects seem to be present in particular: a willingness and ability to take care of confidential knowledge (see also Bulgurcu et al., 2010). Here, empirical evidence points towards what these proactive means entail. First, we found specific indicators that managers can pay attention to: indicators of the applicant's willingness to limit unwanted knowledge leaking include the applicant's openness about previous employers. The applicant's openness about the previous employer is a good indicator on how the employee behaves and likely will behave later on. However, the evaluation is mostly based on impressions, and cues for (lack of) integrity need to be actively searched for. The applicant's willingness to limit unwanted knowledge leaking and the means to evaluate the applicant's ability to do this can be assessed in different manners. The means to evaluate the willingness (referring the closest to evaluating the benevolence) of a potential employee to protect knowledge from leaking can be done by evaluating the employment history, applying psychological tests and conducting background checks, as well as using the intuition of the experienced recruiters regarding their assessment of the applicant's willingness to behave ethically towards the employer. The proactive means to evaluate ability (referring to evaluating the potential employee's ability in terms of awareness about needs related to knowledge protection) such as using referrals and assessing awareness of the applicant on responsibilities related to knowledge protection are important. This evaluation can be done by bluntly testing the applicant's knowledge on confidentiality issues in general. In sum, companies should in their recruitment process look for candidates with a strong sense of justice and a willingness to do the right thing.

The difficulty of evaluating the indicators of an applicant's willingness to limit unwanted knowledge leaking - other than by impressions of their eagerness to share their former employer's knowledge - may indicate that there are no proper procedures available for such evaluation or, on the other hand, it could be that the companies are confident that reactive mechanisms suffice in case the responsibility of protecting confidential knowledge of the company is breached. However, the limitation of reactive mechanisms is that they are used only after the damage has been done. The confidential knowledge that is lost cannot be redeemed once it has leaked out, which can have detrimental effects for value capture in the case of trade secret protected innovations, for example. Earlier studies have suggested that reactive approach can include not only sanctions and monitoring but also rewards for appropriate conduct, but the problem is that in most cases the rewards have 
been found quite redundant (Bulgurcu et al., 2010). Hence, a proactive approach might produce better results.

\subsection{Proactive approach of evaluating commitment}

According to our findings, the proactive assessment regarding commitments is about understanding the indicators of commitment and assessing the applicant by means that have the potential to reveal something about the future commitment of the applicant. Finally, the contextual aspects also need to be acknowledged.

The indicators of commitment include the assessment of stability of the applicant, and looking at duration of their previous employments and enquiring them about the reasons behind these durations if they were to be shorter than expected in the field (considering for example the learning curve of an industry).

Applying means to assess commitment that were found in the analysis meant applying holistic interviews (classic HR, behaviour-based, and technical interviews; see Appendix A), applying psychological tests, and assessing motivation, especially the intrinsic motivation and match between the task and the potential employee's orientation with such knowledge work. It is important that multiple, both objective and subjective - evaluation mechanisms are applied. For example, interviews are associated with the risk that individual interviewers are biased to assess the person-organisation fit in terms of similarity to themselves, for example, or that they are geared towards specific attributes of the applicants while neglecting important aspects (see Posthuma et al., 2002; Hough et al., 2001) $)^{1}$.

Furthermore, our study suggests that the context of commitment issues come into play already at the recruitment phase: especially worker mobility is something acknowledged by managers. We find the assessment of the competitive situation being one issue that the managers need to pay attention to in their proactive assessment of risks related to knowledge leaving. This aspect is brought up also in current literature, although oftentimes it sees mobility as beneficial rather than risky (Rosenkopf and Almeida, 2003; Singh and Agrawal, 2011; Song et al., 2003). Nevertheless, it seems that in markets where worker mobility is high, the commitment indicators may need to be set to a different level compared to other areas: what is sufficient needs to be considered. What makes assessing commitment issues even more challenging is the fact that turnover among knowledge workers has been noted to be significantly higher than for other employee groups (Despres and Hiltrop, 1995). Therefore, various points of view need to be considered simultaneously, and it may be that the preparation for knowledge protection needs to be done in different areas by utilising proactive, reactive, HRM-related and other mechanisms.

Figure 1 below summarises the above discussion by positioning the proactive approach and its elements with regard to knowledge leaving and leaking risk (and reactive HRMrelated aspects).

\footnotetext{
${ }^{1}$ We would like to thank an anonymous reviewer for this insight.
} 


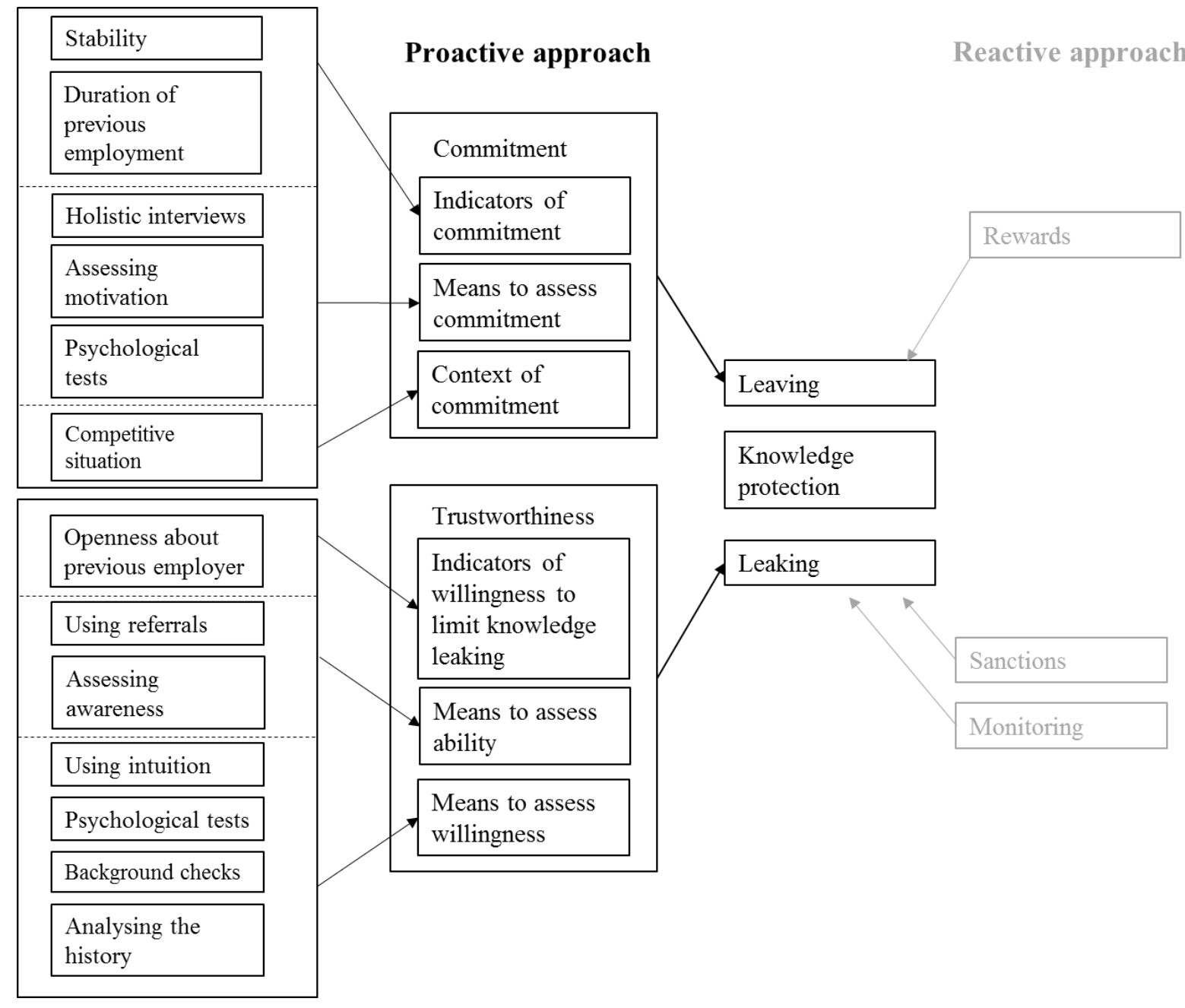

Figure 1 Proactive means in mitigating knowledge leaving and leaking for knowledge protection.

\section{Conclusions}

This study contributes to the existing knowledge on the use of HRM-related protection mechanisms in the innovating organisations' knowledge management processes in several ways. Firstly, this study identifies different types of HRM-related mechanisms that can be used to govern knowledge risks of leaking and leaving in the context of recruiting R\&D personnel. Secondly, the paper makes an explicit distinction, to our knowledge for the first time, between the reactive and proactive means of HRM-protection. Thirdly, the paper identifies two areas of evaluation - commitment and trustworthiness - where proactive HRM mechanisms can be effectively utilised. Our examination suggests that different types of knowledge risks relate to different types of proactive evaluation of employees and their behaviour and conduct: Assessing commitment is connected to dealing with 
knowledge leaving types of risks, and assessing ability and trustworthiness of the employees is linked to knowledge leaking. Each of these is then addressed through specific means. Fourthly, our approach to employers' evaluation of the employees' trustworthiness is filling a gap in trust research, where research related to such activity is still rather scarce. In particular, the tendency is to conduct research on horizontal organisational trustrelationships, leaving vertical, top-down evaluations unnoticed, especially in the case of potential employees. Our study suggests that there are indeed ways to evaluate these issues proactively, even with the inherent challenges in doing so $^{2}$.

Depending on whether the risks perceived in the companies are related to knowledge leaking or leaving, the evaluations conducted in these areas can assist in mitigating the challenges related to knowledge protection. Earlier research has shown that there is not that much that can be done about knowledge leaving by traditional HRM-related means (see, e.g., Mowday, 1984; Johari et al., 2012; Hom and Kinicki, 2001), but this study contributes to the issue by introducing the proactive approach and suggesting the idea of taking the leaving-issues into consideration already in the recruiting phase. Such an approach eases avoiding (at least some part of the) misplaced recruitments in the first place, and thus secures better chances for the success of the proactive (as well as reactive) mechanisms during the course of the employment relationship.

The results should benefit firms in industries with a high emphasis on R\&D and heavy investment in personnel. Managing employees' movement and communication is typically approached from a different angle, i.e. from the point of view of promoting knowledge sharing and learning (Filatotchev, et al., 2011; Rosenkopf and Almeida, 2003; Singh and Agrawal, 2011; Song et al., 2003). The potential related to knowledge protection and innovation appropriation through the proactive HRM mechanisms may go unnoticed. Firms can learn how to proactively prepare for the risks already in the recruiting phase, which, based on the empirical findings, is a phase where these issues could be managed intentionally. We can argue that proactive preparation of companies for employee-related knowledge risks calls for a new conscious dimension in recruiting, and that it needs to be acknowledged by people taking part in the selection process. Then, the decisions about the risks to be taken can be better informed and calculated. We argue that companies need to have a person (or people) aware of the two types of risks who is familiar with the R\&D field of the company (also to take part in the recruiting process), who has the sensitivity to detect issues related to these, and who is able to evaluate the levels of capability and commitment of the applicant in terms of the issues we present in figure 1.

We acknowledge that our study is limited and that there are multiple areas for closer review. For example, while we did not discuss this aspect more in this paper, there are differences with regard to what extent the recruitment phase is actually utilised to prepare for knowledge protection, and how well individual mechanisms serve in revealing potential problems. However, as the phenomenon of addressing knowledge risks during recruitment is certainly present, examining how well this aspect is managed in firms and what kind of influences the "goodness" of the recruitment process has on later appropriability can reveal relevant information. This study hopefully provides the stepping stones for further research.

\footnotetext{
${ }^{2}$ Consider, for instance, the poor reliability of interviews (Posthuma et al., 2002; Hough et al., 2001)
} 


\section{References}

Alvesson, M (2000). Social identity and the problem of loyalty in knowledge-intensive companies. Journal of Management Studies, 37(8), 1101 - 23.

Belderbos, R and D Somers (2015). Do technology leaders deter inward R\&D investments? Evidence from regional R\&D location decisions in Europe. SSRN Electronic Journal, 03/2015.

Bligh, MC, CL Pearce and JC Kohles (2006). The importance of self-and shared leadership in team based knowledge work: A meso-level model of leadership dynamics. Journal of Managerial Psychology, 21(4), 296-318.

Blumer, H. (1954). What is wrong with social theory? American Sociological Review, 18, 3-10.

Bowen, GA (2006). Grounded theory and sensitizing concepts. International Journal of Qualitative Methods, 5(3), 12-23.

Brower, HH, SW Lester, MA Korsgaard and BR Dineen (2009). A closer look at trust between managers and subordinates: Understanding the effects of both trusting and being trusted on subordinate outcomes. Journal of Management, 35(2), 327-347.

Bulgurcu B, H Cavusoglu and I Benbasat (2010). Information security policy compliance: An empirical study of rationality-based beliefs and information security awareness. MIS Quarterly, 34, 523-548.

Butler, JK (1991). Toward understanding and measuring conditions of trust: Evolution of a conditions of trust inventory. Journal of Management, 17, 643-663.

Chang, JY, JN Choi and MU Kim (2008). Turnover of highly educated R\&D professionals: The role of pre-entry cognitive style, work values and career orientation. Journal of Occupational and Organizational Psychology, 81: 299-317.

Cho, YJ and L Perry (2012). Intrinsic motivation and employee attitudes: Role of

managerial trustworthiness, goal directedness, and extrinsic reward expectancy. Review of Public Personnel Administration, 32(4), 382-406.

Cisco corp. (2014) Cisco connected world technology report, available at: http://www.cisco.com/c/en/us/solutions/enterprise/connected-world-technologyreport/index.html.

Colbert, AE and IWG Kwon (2000). Factors related to the organizational commitment of college and university auditors. Journal of Managerial Issues, 12(4): 484-501.

Currie, G and M Kerrin (2003). Human resource management and knowledge management: Enhancing knowledge sharing in a pharmaceutical company. International Journal of Human Resource Management, 14(6), 1027-1045.

Dahlander, L and DM Gann (2010). How open is innovation? Research policy, 39(6), 699-709.

Despres, C and JM Hiltrop (1995). Human resource management in the knowledge age: current practice and perspectives on the future. Employee Relations, 17(1), 9-23.

Dosi, G, L Marengo and C Pasquali (2006). How much should society fuel the greed of innovators? On the relations between appropriability, opportunities and rates of innovation. Research Policy 35, 1110-1121.

Filatotchev, I, X Liu, J Lu and M Wright (2011). Knowledge spillovers through human mobility across national borders: Evidence from Zhongguancun Science Park in China. Research Policy, 40(3), 453-462. 
Fiorito, J, D Bozeman, A Young and J Meurs (2007). Organizational commitment, human resource practices, and organizational characteristics. Journal of Managerial Issues, 19(2), 186-207.

Franzosi, RP (2006). Content analysis, In Handbook of data analysis, M Hardy and A Bryman (eds.), Thousand Oaks, California: Sage Publications Inc., 547-566.

Gardner, WL, BJ Reithel, CC Cogliser, FO Walumbwa and RT Foley (2012). Matching personality and organizational culture: Effects of recruitment strategy and the five-factor model on subjective person-organization fit. Management Communication Quarterly, 26(4), 585-622.

Gioia, DA, KG Corley and AL Hamilton (2013). Seeking qualitative rigor in inductive research: Notes on the Gioia methodology. Organizational Research Methods 16, 15-31.

Glaser, BG (1978). Theoretical sensitivity: Advances in the methodology of grounded theory. Mill Valley, CA: Sociology Press.

Grossman, GM. and E Helpman (1991). Trade, knowledge spillovers, and growth. European Economic Review, 35(2), 517-526.

Haesli, A and P Boxall (2005). When knowledge management meets HR strategy: An exploration of personalization-retention and codification-recruitment configurations. International Journal of Human Resource Management, 16(11), 1955-1975.

Han, Z and FJ Froese (2010) Recruiting and retaining R\&D professionals in China. International Journal of Technology Management, 51(2/3/4), 387-408.

Hannah, DR (2005). Should I keep a secret? The effects of trade secret protection procedures on employees' obligations to protect trade secrets. Organization Science, 16(1), 71-84.

Hannah DR and K Robertson (2015). Why and how do employees break and bend confidential information protection rules? Journal of Management Studies, 52(3), 381413.

Hofer-Alfeis, J (2008). Knowledge management solutions for the leaving expert issue. Journal of Knowledge Management, 12(4), 44-54.

Hom, PW and AJ Kinicki (2001). Toward a greater understanding of how dissatisfaction drives employee turnover. Academy of Management Journal, 44(5), 975987.

Horwitz, F, CT Heng and A Quazi (2003). Finders keepers? Attracting, motivating, and retaining knowledge workers. Human Resource Management Journal, 13(4), 23-44.

Hough, LM, FL Oswald and RE Ployhart (2001). Determinants, detection and amelioration of adverse impact in personnel selection procedures: Issues, evidence and lessons learned. International Journal of Selection and Assessment, 9(1-2), 152-194.

Hurmelinna-Laukkanen, P, JFS Gomes and H Olander (2015), What did you expect to happen? Aligning HR practices with knowledge management outcomes. 15th EBES Conference, 8-10 January, 2015, Lisbon, Portugal.

Johari, J, T Yean, Z Adnan, KK Yahya and MN Ahmad (2012). Promoting employee intention to stay: Do human resource management practices matter?, International Journal Economics and Management, 6(2), 396-416.

Kristof, AL (1996). Person-organization fit: An integrative review of its conceptualizations, measurement, and implications. Personnel Psychology, 49(1), 1-49.

Larzelere, R and T Huston (1980). The dyadic trust scale: Toward understanding interpersonal trust in close relationships. Journal of Marriage and the Family, 42, 595-604.

Liebeskind, JP (1996). Knowledge, strategy, and the theory of the firm. Strategic Management Journal, 17, 93-107. 
Liebeskind, JP (1997). Keeping organizational secrets: protective institutional mechanisms and their costs. Industrial and Corporate Change, 6(3), 623-663.

Lin, CY, TH Kuo (2007). The mediate effect of learning and knowledge on organizational performance. Industrial Management \& Data Systems, 107(7), 1066-1083.

Mayer, RC, JH Davis and D Schoorman (1995). An integrative model of organizational trust. Academy of Management Review, 20, 709-734.

Mitchell, TR, BC Holtom and TW Lee (2001). How to keep your best employees: developing an effective retention policy. Academy of Management Executive, 15(4), 96109.

Mowday, RT (1984). Strategies for adapting to high rates of employee turnover. Human Resource Management, 23(4), 365-380.

Norman, PM (2001). Are your secrets safe? Knowledge protection in strategic alliances. Business Horizons, 44(6), 51-60.

Norman, PM (2002). Protecting knowledge in strategic alliances, Resource and relational characteristics. Journal of High Technology Management Research, 13, 177202.

Olander, H and P Hurmelinna-Laukkanen (2015). The road to trouble is paved with good intentions. Proceedings of the Academy of Management annual meeting, August 912th 2015, Vancouver, Canada.

Olander, H and P Hurmelinna-Laukkanen (2015). Perceptions of employee knowledgerisks in multinational, multilevel R\&D organizations - Managing knowledge leaking and leaving. International Journal of Innovation Management, 19(3), 1540006-1-1540006-28.

Olander, H, P Hurmelinna-Laukkanen and M Vanhala (2014). Mission: possible but sensitive - Knowledge protection mechanisms serving different purposes. International Journal of Innovation Management, 18(6), 1440012-1-1440012-24.

O'Neill, BS and M Adya (2006). Knowledge sharing and the psychological contract. Journal of Managerial Psychology, 22(4), 411-436.

O'Reilly, CA, J Chatman and DF Caldwell (1991). People and organizational culture: A profile comparison approach to assessing person-organization fit. Academy of Management Journal, 34(3), 487-516

Posthuma, RA, FP Morgeson and MA Campion (2002). Beyond employment interview validity: A comprehensive narrative review of recent research and trends over time. Personnel Psychology, 55(1), 1-82.

Rosenkopf, L and P Almeida (2003). Overcoming local search through alliances and mobility. Management Science, 49(4), 751-766.

Rousseau, DM and KA Wade-Benzoni (1994). Linking strategy and human resource practices: how employee and customer contracts are created. Human Resource Management, 33(39), 463-489.

Hurmelinna-Laukkanen P and K Puumalainen (2007). The nature and dynamics of appropriability: strategies for appropriating returns on innovation. $R \& D$ Management, 37 , $95-112$.

Paré, G, M Tremblay and P Lalonde (2001). Workforce retention: What do IT employees really want? In Proceedings of the 2001 ACM SIGCPR conference on Computer personnel research. 1-10.

Patton, MQ (2002). Qualitative research and evaluation methods. (3rd ed.) Thousand Oaks, CA: Sage.

Silverman, D (2005). Doing qualitative research. Sage Publications, Thousand Oaks, CA. 
Singh, J and A Agrawal (2011). Recruiting for ideas: How firms exploit the prior inventions of new hires. Management Science, 57(1), 129-150.

Sitkin, SB, and NL Roth (1993). Explaining the limited effectiveness of legalistic "remedies" for trust/distrust. Organization Science, 4, 367-392.

Song, J, P Almeida and G Wu (2003). Learning-by-hiring: when was mobility more likely to facilitate interfirm knowledge transfer? Management Science, 49, 4, 351-365.

Storey, J. and Quintas, P. (2001). Knowledge Management and HRM. In Storey, J. (ed.) Human Resource Management: a Critical Text. London: Thomson Learning, pp. 339-63.

Todorova, G and B Durisin (2007). Absorptive capacity: Valuing a reconceptualization. Academy of Management Review, 32, 774-786.

Tyler, TR (2003). Trust within organisations. Personnel Review, 32(5), 556-568.

Tyler, TR and SL Blader (2005). Can businesses effectively regulate employee conduct? The antecedents of rule following in work settings. Academy of Management Journal, 48, 1143-1158.

Tzafrir, SS (2005). The relationships between trust, HRM practices and firm performance, International Journal of Human Resource Management, 16(9), 1600-1622.

Vanhala, M, and R Ahteela (2011). The effect of HRM practices on impersonal organizational trust. Management Research Review, 34(8), 869-888.

West, J (2006). Does appropriability enable or retard open innovation. In: Chesbrough, H, W Vanhaverbeke and J West (Eds.). Open Innovation: Researching a New Paradigm. Oxford university press, 109-133.

Yin, RK (2003). Case study research, design and methods. 3rd edition, Sage Publications, Thousand Oaks. 
Appendix A Illustrative example quotes and first order concepts leading to aggregated dimensions related to knowledge leaving

\begin{tabular}{|c|c|}
\hline $\begin{array}{l}\text { Quote (\#N of interviewee Industry/country/level within } \\
\text { organization) }\end{array}$ & $1^{\text {st }}$ order concepts \\
\hline $\begin{array}{l}\text { "In the whole China, it's about } 75 \text { per cent who are not, how } \\
\text { to say, committed to their current position." } \\
\text { \#23 Eng./China/Mgr. } \\
\text { "Now as the market situation is worse again [for the } \\
\text { company], then naturally we are losing some of our best } \\
\text { competence because of that." \#7 ICT/US/Str. }\end{array}$ & Competitive situation \\
\hline $\begin{array}{l}\text { "-- And of course potential employees, especially in superior } \\
\text { positions, will be sent to take the psychological tests. The } \\
\text { superiors will know what to think after tests, interviews and } \\
\text { CVs about the content knowledge.." \#5 ICT/FIN/Mgr. }\end{array}$ & Psychological tests \\
\hline $\begin{array}{l}\text { "We do consider the motivation of employees, when } \\
\text { recruiting, but also when having to lay off or dismissing." \#7 } \\
\text { ICT/FIN/Str. } \\
\text { "You want to know if someone is passionate about their } \\
\text { work. If this guy is more interested in academia, he's not } \\
\text { going to stay here for a long time.." \#8 ICT/US/Oper. }\end{array}$ & Assessing motivation \\
\hline $\begin{array}{l}\text { "We want to have long term employees." \#7 Eng./FIN/Str. } \\
\text { "I would want the stable one." \#22 Eng./China/Team leader } \\
\text { "They should work for [us] at least five years." \#23 } \\
\text { Eng./China/Mgr. } \\
\text { "Eight years is the shortest employment period for a person } \\
\text { that is with us. "\#21 Eng./US/Str. }\end{array}$ & $\begin{array}{l}\text { Search for long term } \\
\text { employees - Stability }\end{array}$ \\
\hline $\begin{array}{l}\text { "If a potential employees' CV shows that he has been } \\
\text { working in previous jobs for only three or four years, I can } \\
\text { understand, I can accept. Maybe you have some background } \\
\text { story behind. That is cultural I can accept. But if only one } \\
\text { year/job, I will not accept. It seems that they don't know } \\
\text { what they want." \#23 Eng./China/Mgr. }\end{array}$ & $\begin{array}{l}\text { Assessing duration of } \\
\text { previous employment }\end{array}$ \\
\hline $\begin{array}{l}\text { "We measure commitment of a potential employee by having } \\
\text { several interviewers present. The future colleagues, HR } \\
\text { department, the recruiting superior." \#8 ICT/US/Oper. } \\
\text { "We have three types of interviews: classic HR interview, } \\
\text { behavior based interview (peer experience, role in teams, } \\
\text { projects, contribution and achieving goals, how to overcome } \\
\text { challenges etc.) and lastly technical interviews." \#13 } \\
\text { ICT/China/Team leader }\end{array}$ & Holistic interviews \\
\hline
\end{tabular}


Appendix B Illustrative example quotes and first order concepts leading to aggregated dimensions related to knowledge leaking

\begin{tabular}{|c|c|}
\hline $\begin{array}{l}\text { Quote (\#N of interviewee Industry/country/level within } \\
\text { organization) }\end{array}$ & $1^{\text {st }}$ order concepts \\
\hline $\begin{array}{l}\text { "If a person speaks a lot about their previous collaborations } \\
\text { in job interviews, they will probably do the same if leaving } \\
\text { [our company]." \#18 ICT/US/Team leader } \\
\text { "So you ask questions about their previous jobs and see if } \\
\text { they are willing to just give away information easily. If they } \\
\text { do, then you may wanna think twice before you hire them. If } \\
\text { a person is that nature then it's not very easy to change } \\
\text { them." \#15 Eng./US/Str. }\end{array}$ & $\begin{array}{l}\text { Openness about previous } \\
\text { employer }\end{array}$ \\
\hline $\begin{array}{l}\text { "Picking up signals. If you see something from the resumes, } \\
\text { or from the conversation that you're having, or the questions, } \\
\text { the way they're answering that might raise a red flag to you, } \\
\text { then you would use your judgment." \#25 Eng./US/Mgr. } \\
\text { "Difficult to evaluate, intuition needed. Sense of duty is } \\
\text { evaluated, important personality issue during recruiting." } \\
\text { \#26 Eng./China/Team leader } \\
\text { "General trustworthiness evaluated by the recruiters by } \\
\text { intuition." \#17 ICT/US/Oper. }\end{array}$ & $\begin{array}{l}\text { Using intuition to assessing } \\
\text { the trustworthiness }\end{array}$ \\
\hline $\begin{array}{l}\text { "I would concentrate more attention on making sure that he } \\
\text { understands what confidentiality is, and how to hold this } \\
\text { information in the small circle of the reliability group." \#21 } \\
\text { Eng./US/Str. }\end{array}$ & Assessing awareness \\
\hline $\begin{array}{l}\text { "... we have the psychological tests for them." "6 } \\
\text { ICT/FIN/Str. } \\
\text { "also psychological tests, try to evaluate moral rather than } \\
\text { technical basis." \#17 Eng./China/Str. } \\
\text { “...we do have the personality tests in use." \#2 } \\
\text { Eng./FIN/Mgr. }\end{array}$ & $\begin{array}{l}\text { Psychological tests or } \\
\text { personality tests }\end{array}$ \\
\hline $\begin{array}{l}\text { "I like somebody to recommend, and not from the internet." } \\
\text { \#22 Eng./China/Team leader }\end{array}$ & Use of referrals \\
\hline $\begin{array}{l}\text { "we will do the country-related background checks in each } \\
\text { market. At least this way we'll know that there is no criminal } \\
\text { background in terms of industrial espionage or alike." \#5 } \\
\text { ICT/FIN/Mgr. }\end{array}$ & Background checks \\
\hline "Work history tells a lot." \#17 ICT/US/Oper. & $\begin{array}{l}\text { Analysing the history of } \\
\text { applicants }\end{array}$ \\
\hline
\end{tabular}

